\title{
A Post-Acute Ocular Tolerability Comparison of Topical Reproxalap $0.25 \%$ and Lifitegrast $5 \%$ in Patients with Dry Eye Disease
}

\author{
David McMullin' \\ David Clark' \\ Bill Cavanagh (D) \\ Paul Karpecki $\mathbb{D}^{2}$ \\ Todd C Brady (D)'
}

'Aldeyra Therapeutics, Inc, Lexington, MA, USA; ${ }^{2}$ Kentucky Eye Institute, Lexington, KY, USA
Correspondence: Todd C Brady

Aldeyra Therapeutics, Inc, I3 I Hartwell

Avenue, Suite 320, Lexington, MA, 0242I,

USA

Tel + I 78I 76I-4904

Email tbrady@aldeyra.com
Purpose: To assess the subjective eye drop experience of patients with dry eye disease (DED) over approximately 1 hour after a single dose of two formulations of reproxalap versus lifitegrast.

Methods: Two formulations of topical ocular reproxalap $0.25 \%$ were evaluated versus lifitegrast ophthalmic solution 5\% in patients with DED in a single-center, double-masked, active-comparator, single-dose crossover clinical trial. Nineteen patients had test article topically administered to both eyes. Treatments were administered 2 to 4 days apart. Comfort assessments, including ocular discomfort, blurry vision, and dysgeusia assessments; ocular descriptive assessments; quality of life assessments; and overall experience questions were completed after each treatment over one hour, beginning at 90 seconds.

Results: Both reproxalap formulations scored better in ocular discomfort score (ODS), blurry vision, and dysgeusia assessments than lifitegrast at each timepoint and cumulatively over all time points after instillation. There were lower rates of negative responses for both reproxalap formulations compared to lifitegrast across ocular discomfort, blurry vision, and dysgeusia assessments, and the durations of negative responses were shorter with reproxalap than with lifitegrast. The reproxalap groups experienced fewer quality of life impacts. No significant safety findings were observed following reproxalap or lifitegrast administration.

Conclusion: The reproxalap eye drop experience over 1 hour after instillation was superior to that of lifitegrast. There were no statistically significant differences between reproxalap groups for ODS, blurry vision, or dysgeusia. The improved performance of reproxalap with regard to the most commonly reported side effects of lifitegrast (ie, ocular discomfort, blurry vision, and dysgeusia) may result in greater patient adherence and lower discontinuation rates.

Keywords: RASP inhibitor, dry eye disease, inflammation, reproxalap, lifitegrast, eye drop comfort

\section{Plain Language Summary}

Dry eye disease (DED) is a complex, chronic condition characterized by ocular discomfort, visual disturbance, tear film instability, increased tear osmolarity, conjunctival redness, and inflammation of the ocular surface that in severe cases can lead to loss of vision. Treatment options for DED consist of artificial tears, anti-inflammatory agents, antibiotics, and immunosuppressants. The comfort associated with eye drop instillation and the overall tolerability of treatment strongly impact patient preferences and, by extension, the effectiveness of the prescribed treatment. Currently, lifitegrast is one of only two drugs approved for the chronic treatment of DED. The most common side effects associated with lifitegrast are ocular 
irritation, blurred vision, and dysgeusia. Approximately twothirds of patients with DED prescribed lifitegrast discontinue treatment after a median of 1 month. Although post-instillation site irritation is characteristic of most prescription eye drops, the objective of this clinical trial was to compare the eye drop experience of topical ocular reproxalap versus lifitegrast in subjects with DED after post-instillation site discomfort ceased. Reproxalap consistently scored higher than lifitegrast on the measures of drop comfort, including ocular discomfort, blurry vision, dysgeusia, descriptive drop comfort, quality of life, and overall experience. The superior performance of reproxalap with regard to the most commonly reported side effects of lifitegrast may result in greater patient adherence and lower discontinuation rates.

\section{Introduction}

Dry eye disease (DED) is a complex, chronic condition characterized by ocular discomfort, visual disturbance, tear film instability, increased tear osmolarity, conjunctival redness, and inflammation of the ocular surface that in severe cases can lead to loss of vision. ${ }^{1}$ Estimates indicate that DED afflicts 16.4 million adults in the United States or $6.8 \%$ of the adult population. ${ }^{2,3}$ DED, which is usually incited by inflammation that requires long-term treatment to manage effectively, imposes a significant economic and humanistic burden in the United States, and patients with DED experience higher rates of depression and anxiety, increased lost work productivity, and decreased quality of life (QoL). ${ }^{4-10}$

Treatment options for DED consist of artificial tears, antiinflammatory agents, antibiotics, and immunosuppressants. ${ }^{4}$ Aside from topical corticosteroids, which lead to ocular toxicity and must be restricted to short-term use, ${ }^{11,12}$ cyclosporine ophthalmic emulsion $0.05 \%$ and lifitegrast ophthalmic solution $5 \%$ are the only two anti-inflammatory ophthalmic drugs approved by the US Food and Drug Administration for the treatment of DED, ${ }^{4,13}$ and lifitegrast is the only drug approved for the treatment of the signs and symptoms of DED. ${ }^{13}$ A recent retrospective study examining DED treatment adherence among 9772 patients with at least one prescription claim for cyclosporine or lifitegrast found that approximately two-thirds of patients discontinued treatment, with median discontinuation times of 3 months for cyclosporine and 1 month for lifitegrast. ${ }^{4}$ The most common side effects associated with lifitegrast are ocular irritation, blurred vision, and dysgeusia, ${ }^{14}$ and the most common side effect of cyclosporine is ocular irritation, ${ }^{4}$ all of which can occur after the initial instillation site discomfort that is characteristic of most prescription eye drops. ${ }^{15}$ Both the comfort associated with treatment instillation and the overall treatment tolerability strongly impact patient preferences and, by extension, the effectiveness of prescribed treatments. ${ }^{16}$ A clear unmet need exists in the population of patients with DED for novel therapeutics with improved eye drop experience profiles. ${ }^{17,18}$

Reproxalap is a novel reactive aldehyde species inhibitor that covalently binds free aldehyde targets and has been shown in Phase $2 \mathrm{a}^{19}$ and Phase $2 \mathrm{~b}^{20}$ clinical trials to be well tolerated and effective in mitigating the symptoms of DED. Reproxalap has also been shown to be well tolerated and effective in a Phase 3 clinical trial in allergic conjunctivitis $^{21}$ and noninferior to topical corticosteroid use in a Phase 2 trial in patients with noninfectious anterior uveitis. $^{22}$ The objective of this head-to-head crossover clinical trial was to compare the post-acute eye drop experience of two formulations of topical ocular reproxalap (differing only with regard to a modest percent change in weight/ volume of an excipient) versus lifitegrast in subjects with DED after initial instillation site discomfort, which is characteristic of most prescription eye drops, peaks. ${ }^{15}$

\section{Methods}

\section{Study Design}

Nineteen patients with DED were enrolled in a singlecenter, active comparator, single-dose crossover Phase $1 \mathrm{~b}$ clinical trial designed to assess the subjective eye drop experience over approximately 1 hour after a single dose of two formulations of reproxalap versus lifitegrast.

The trial consisted of three visits over 7 days with an approximately 3-day washout period between treatment visits. At each visit, one of the following treatments was applied to both eyes by an unmasked technician in the following sequence: lifitegrast ophthalmic solution 5\%, reproxalap $0.25 \%$ standard formulation (SF), or reproxalap $0.25 \%$ novel formulation (NF). The novel formulation was similar to the standard formulation, except that the percent weight/volume of an excipient was modestly increased. Over the course of the trial, each patient received each treatment. Subjects were masked to treatment, as were investigators and all clinical site personnel except technicians who administered the eye drops.

\section{Patients and Treatment}

Patients were adults aged $\geq 18$ years with a reported history of dry eye in both eyes for $\geq 6$ months prior to screening. Patients were excluded for any clinically significant slit- 
lamp findings at screening, including active blepharitis, meibomian gland dysfunction, lid margin inflammation, or ocular allergies that required therapeutic treatment and that may have interfered with the conduct of the trial. Other exclusion criteria included contact lens use within 7 days of screening; eye drop use within 2 hours of screening; use of ophthalmic cyclosporine within 30 days of screening; planned ocular or lid surgeries over the trial period or any ocular surgeries within 6 months of screening; anticipated change in punctal plug status during the trial; and use of topical ophthalmic prescription medication that could not be discontinued for the duration of the trial. Patients who had previously participated in any reproxalap ophthalmic solution clinical trial or had previously taken lifitegrast ophthalmic solution were also excluded.

\section{Assessments}

In order to assess subacute tolerability after the postinstillation site discomfort that is characteristic of most prescription eye drops, assessments began $90( \pm 60)$ seconds after instillation. Additional assessments were made at $3,5,10,15,30$, and 60 minutes post-dose. Ocular discomfort score (ODS) was rated from 0 to $10(0=$ no discomfort and $10=$ maximum discomfort), blurry vision was rated from 0 to $10(0=$ no blurriness [normal vision] and $10=$ maximum blurriness), and dysgeusia was rated from 0 to $10(0=$ no taste and $10=$ maximum unpleasant taste). In addition, a descriptive drop comfort assessment was conducted in which the patients were asked to select from a list of positive and negative descriptive terms describing ocular discomfort, quality of vision, and dysgeusia. After study drug instillation, a QoL questionnaire was conducted in which patients were asked two QoL gating questions regarding blurry vision or bad taste from taking the study drug; in the event of affirmative answers to the gating questions, follow-up questions were asked about the QoL impact of the blurred vision or bad taste.

Safety was assessed regularly across the trial visits. To exclude subjects with clinically significant retinal disease, an undilated fundoscopy safety assessment was conducted during Visit 1. Visual acuity and slit-lamp evaluation (without staining) safety assessments were conducted at every visit. Safety was assessed via adverse events (AEs). All AEs spontaneously reported by the subject and/or in response to an open question from study personnel or revealed by study procedures were recorded. In the absence of clinical sequelae, ocular discomfort, blurriness, and dysgeusia were the outcome measures of the clinical trial and therefore not considered AEs.

\section{Statistical Analysis}

The trial was exploratory and not formally powered. A total of approximately 20 subjects was deemed sufficient by the investigators to obtain tolerability and safety information in the context of DED. ODS, blurry vision ratings, and dysgeusia ratings were reported by the patients and summarized descriptively (ie, n, mean, standard deviation, median, minimum, and maximum) by time point and treatment group. A mixed model repeated measures (MMRM) analysis was performed to compare ocular discomfort score, blurry vision, and taste disturbance of reproxalap SF versus lifitegrast and reproxalap NF versus lifitegrast. To confirm the clinical relevance of the MMRM results, overall negative responder analyses were compared across treatment groups using a generalized estimating equation approach. Consistent with minimal clinically important differences for acute increases in discomfort, ${ }^{23}$ scores of $\geq 3$ were used to identify negative responders for ocular discomfort, blurry vision, and dysgeusia. Negative responder duration percentages in each group were tallied according to tercile. The percentage of positive and percentage of negative descriptive term values were calculated by treatment group.

\section{Results}

\section{Baseline Characteristics}

A total of 27 patients were screened. Nineteen patients were enrolled and 17 patients completed the trial. Two patients were discontinued for administrative reasons. Baseline demographic characteristics for the patient cohort are shown in Table 1. All patients had a history of DED for $\geq 6$ months. None of the patients had clinically significant slit lamp or fundus photography findings.

\section{Tolerability Ocular Discomfort}

As assessed by MMRM analysis, the ODS rating reported in the lifitegrast group over all time points in aggregate was greater than that reported for the reproxalap SF and reproxalap NF groups $(P=0.0082$ and $P=0.0001$, respectively, Figure 1A). An ODS negative responder analysis over time was conducted, wherein negative responders were defined as patients reporting ODS score $\geq 3$ (scale $0-10)$. Over all time points, the odds of negative response 
Table I Baseline Demographics and Clinical Characteristics

\begin{tabular}{|l|c|}
\hline & All Patients $\mathbf{n}=\mathbf{1 9}$ \\
\hline $\begin{array}{l}\text { Age (years) } \\
\text { Mean } \\
\text { Median (range) }\end{array}$ & 62.95 \\
\hline Sex & $64(37-72)$ \\
Male & 6 \\
Female & 13 \\
\hline Ethnicity & \\
Hispanic or Latino & 0 \\
Not Hispanic or Latino & 19 \\
\hline Race & \\
White & 19 \\
\hline Iris color, $\mathbf{n}$ (\%) & \\
Blue & 7 \\
Brown & 6 \\
Hazel & 3 \\
Green & 3 \\
\hline
\end{tabular}

were higher in the lifitegrast group (44.9\%) than in the reproxalap SF $(10.5 \%, \mathrm{OR}=0.14, P=0.0006)$ and reproxalap NF groups $(7.4 \%, \mathrm{OR}=0.10, P=0.0003)$ (Table 2$)$. ODS negative responder duration analyses indicated that $63 \%$ of the negative responders in the lifitegrast group experienced an ODS score $\geq 3$ that lasted $\geq 2 \mathrm{~min}$ in length versus $21 \%$ in the reproxalap SF group and $16 \%$ in the reproxalap NF group (Figure 1B). Average negative responder durations were 12.2, 2.2, and 1.2 minutes for the lifitegrast, reproxalap SF, and reproxalap NF groups, respectively.

\section{Blurry Vision Rating}

As assessed by MMRM analysis, the overall blurry vision rating reported in the lifitegrast group over all time points in aggregate was greater than those reported in the reproxalap $\mathrm{SF}$ and reproxalap NF groups $(P=0.0037$ and $P=0.0015$, respectively, Figure 2A). Over all time points, the odds of negative response were higher in the lifitegrast group $(0.1 \%)$ than in the reproxalap SF $(0 \%, \mathrm{OR}=0.25, P=0.0177)$ and reproxalap NF groups $(0 \%, \mathrm{OR}=0.21, P=0.0130)$ (Table 2$)$. Blurry vision negative responder duration analysis showed that $53 \%$ of the negative responders in the lifitegrast group experienced a blurry vision score $\geq 3$ that lasted for any duration, versus $16 \%$ in the reproxalap SF and NF groups (Figure 2B). Average negative responder durations were 7.3, 1.9 , and 1.0 minutes in the lifitegrast, reproxalap SF, and reproxalap NF groups, respectively.

\section{Dysgeusia}

As assessed by MMRM analysis over all time points in aggregate, reported dysgeusia scores were greater for the lifitegrast group versus both the reproxalap SF and NF groups $(P=0.1042$ and $P=0.0184$, respectively, Figure $3 \mathrm{~A})$. Over all time points, the odds of negative response were higher in the lifitegrast group (10.2\%) than in the reproxalap SF $(2.0 \%, \mathrm{OR}=0.18, P=$ $0.0035)$ and reproxalap NF groups $(1.0 \%, \mathrm{OR}=0.09$, $P<0.0001$ ) (Table 2). A dysgeusia negative responder duration analysis indicated that $16 \%$ of the negative responders in the lifitegrast groups experienced a dysgeusia score of $\geq 3$ that lasted any duration, versus $5 \%$ in the reproxalap SF group and $0 \%$ in the reproxalap NF group (Figure 3B). Average negative responder durations were $3.7,0.3$, and 0 minutes in the lifitegrast, reproxalap SF, and reproxalap NF groups, respectively.

\section{Eye Drop Comfort Descriptive Assessment}

Greater percentages of patients in the reproxalap SF group versus the lifitegrast group reported positive responses to ocular comfort descriptors (63\% vs $53 \%$ ), vision comfort descriptors (64\% vs $49 \%$ ), and taste comfort descriptors (65\% vs $29 \%$ ) (Figure 4). Greater percentages of patients in the reproxalap NF group versus the lifitegrast group also reported positive responses to ocular comfort descriptors $(90 \%$ vs $53 \%$ ), vision comfort descriptors ( $84 \%$ vs $49 \%$ ), and taste comfort descriptors (65\% vs 29\%) (Figure 4). Greater QoL impacts caused by blurry vision and bad taste were reported for the lifitegrast group compared to the reproxalap SF and NF groups, with more patients in the lifitegrast group reporting that the blurry vision or bad taste they experienced would either reduce the likelihood of, or prevent entirely, them taking the study drug again (Figure 5A and $\mathrm{B}$ ).

\section{Safety}

Four ocular AEs were experienced by two patients, and two nonocular AEs were experienced by two patients. Ocular AEs included mild ocular soreness lasting 30 minutes (lifitegrast), two instances of moderate burning upon instillation (reproxalap NF and SF, both in the same patient), and mild ocular itching (lifitegrast). All ocular AEs were considered related to the study drug. Non-ocular AEs included mild raspy voice lasting 30 minutes (lifitegrast), which was also considered to be related to the study drug. There were no serious AEs. There were no AE-related treatment 


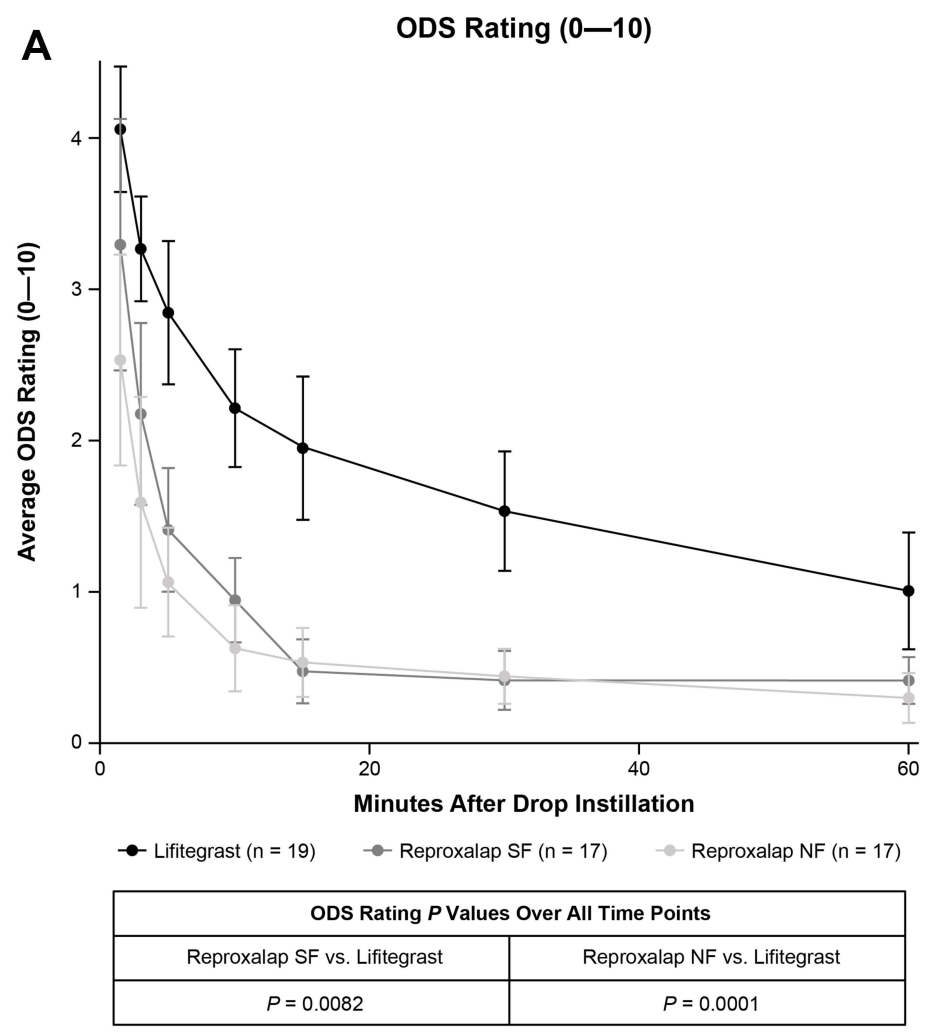

B

Duration of Ocular Discomfort Response

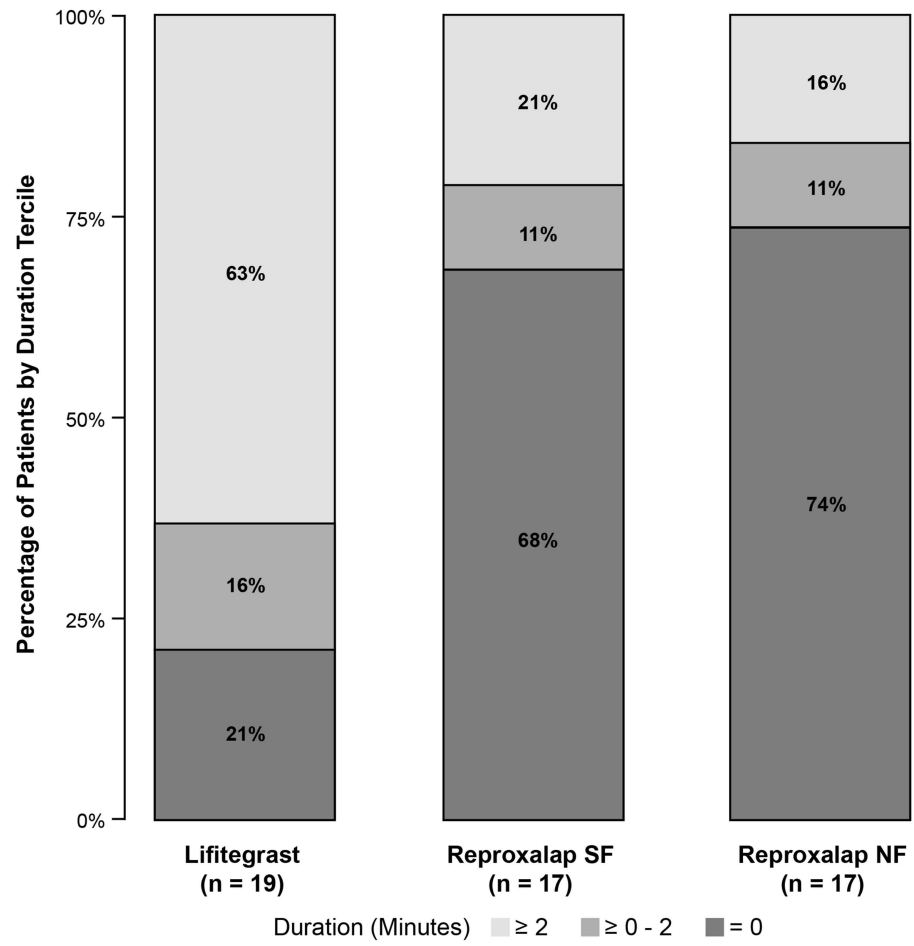

Figure I (A) ODS rating (0-10) of reproxalap SF and reproxalap NF versus lifitegrast. Data are plotted as means \pm SEM. (B) ODS negative responder (score of $\geq 3$ ) duration was analyzed by tercile for each treatment group. 
Table 2 Negative Responder Analysis for Reproxalap SF and Reproxalap NF versus Lifitegrast

\begin{tabular}{|c|c|c|c|c|}
\hline \multirow[b]{2}{*}{ Scale } & \multirow[b]{2}{*}{ Treatment } & \multirow[b]{2}{*}{$\begin{array}{l}\text { Probability of Response } \\
\text { (\%) }\end{array}$} & \multicolumn{2}{|l|}{ vs Lifitegrast } \\
\hline & & & Odds Ratio & $P$ value \\
\hline \multirow[t]{3}{*}{ ODS } & \multirow{3}{*}{$\begin{array}{l}\text { Reproxalap SF } \\
\text { Reproxalap NF } \\
\text { Lifitegrast }\end{array}$} & \multirow{3}{*}{$\begin{array}{l}10.5 \\
7.4 \\
44.9\end{array}$} & 0.14 & 0.0006 \\
\hline & & & 0.10 & 0.0003 \\
\hline & & & & \\
\hline \multirow[t]{3}{*}{ Blurry Vision } & \multirow{3}{*}{$\begin{array}{l}\text { Reproxalap SF } \\
\text { Reproxalap NF } \\
\text { Lifitegrast }\end{array}$} & \multirow{3}{*}{$\begin{array}{l}0.0 \\
0.0 \\
0.1\end{array}$} & 0.25 & 0.0177 \\
\hline & & & 0.21 & 0.0130 \\
\hline & & & & \\
\hline \multirow[t]{3}{*}{ Dysgeusia } & \multirow{3}{*}{$\begin{array}{l}\text { Reproxalap SF } \\
\text { Reproxalap NF } \\
\text { Lifitegrast }\end{array}$} & \multirow{3}{*}{$\begin{array}{l}2.0 \\
1.0 \\
10.2\end{array}$} & 0.18 & 0.0035 \\
\hline & & & 0.09 & $<0.0001$ \\
\hline & & & & \\
\hline
\end{tabular}

discontinuations. No clinically significant changes from baseline were observed with respect to slit lamp and fundus findings.

\section{Discussion}

Although most prescription eye drops lead to transient instillation site discomfort, post-acute tolerability that lasts for $\geq 1$ hour after administration is a critical determinant of compliance, QoL, and treatment efficacy. ${ }^{4,15}$ The present clinical trial assessed the post-acute subjective eye drop experience in patients with DED over 1 hour after instillation of two formulations of reproxalap $0.25 \%$ versus lifitegrast $5 \%$.

Tolerability measures in this clinical trial included ocular discomfort, blurry vision, dysgeusia, descriptive drop comfort, QoL, and an overall experience question. The eye drop experiences associated with instillation of both reproxalap formulations were found to be superior to that of lifitegrast. MMRM analysis of ODS, blurry vision, and dysgeusia scores indicated that reproxalap was better tolerated than lifitegrast across the 1-hour assessment period. There were no statistically significant differences between reproxalap NF and reproxalap SF groups for the ODS, blurry vision, or dysgeusia scores. The clinical relevance of the MMRM results was confirmed with negative responder analyses, the thresholds of which (3 out 10 points for each scale) are in excess of clinically important differences for increases in acute discomfort. ${ }^{23}$ Consistent with the clinically relevant differences in negative response between the reproxalap and lifitegrast groups, the durations of negative responses were less during reproxalap treatment than during lifitegrast treatment.
Reproxalap scored better than lifitegrast during each of the ocular comfort, vision, and dysgeusia components of the drop comfort descriptive assessment. Higher QoL impact scores due to blurry vision and bad taste were reported in the lifitegrast group relative to the reproxalap groups. The results generally confirm the importance of blurry vision and bad taste as factors impacting the QoL of patients by potentially adversely affecting daily activities, treatment compliance, or both. Blurry vision and dysgeusia are side effects of lifitegrast that are well known to patients $^{17}$ and physicians. ${ }^{18}$ In a survey of 96 lifitegrast patients, $50 \%$ and $56 \%$ reported experiencing blurry vision or taste disturbance, respectively, at least sometimes. ${ }^{17}$ For dysgeusia in particular, the real-world incidence appears to be substantially higher than that reported in clinical trials of lifitegrast, and in a survey of 21 physicians, several physicians reported dysgeusia in $\geq 75 \%$ of lifitegrast patients. $^{18}$

No significant safety findings were observed following reproxalap or lifitegrast administration. All slit lamp and fundus findings were clinically insignificant, and there were no changes in slit lamp or fundus findings during the trial. The trial was limited by a small patient population, exploratory design, and lack of formal statistical hypotheses. Future studies are required to further interrogate the broad tolerability differences between DED treatments and may explain differences in compliance and treatment response.

Despite the progressive, chronic nature of DED, which requires long-term treatment to address, it is estimated that most patients discontinue treatment with existing therapies 


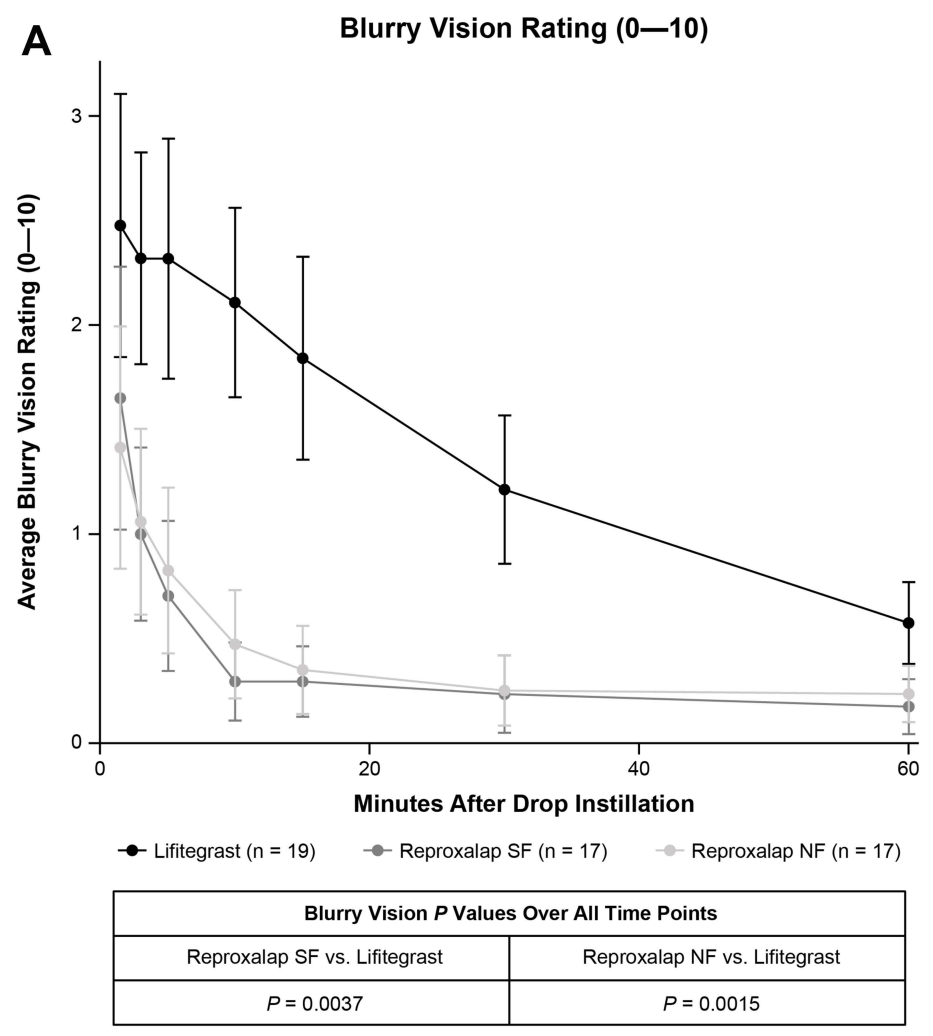

B

Duration of Blurry Vision Response
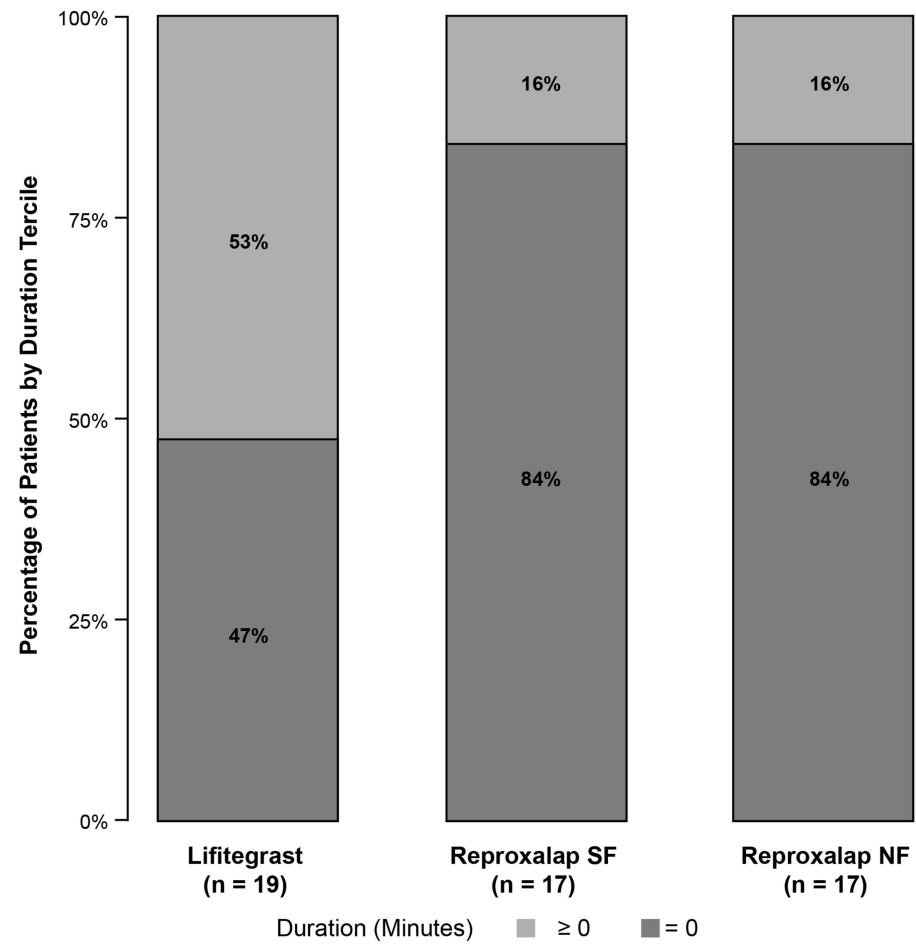

Reproxalap NF $(n=17)$

Figure 2 (A) Blurry vision rating (0-10) of reproxalap SF and reproxalap NF versus lifitegrast. Data are plotted as means \pm SEM. (B) Blurry vision negative responder (score of $\geq 3$ ) duration was analyzed by tercile for each treatment group. The bottom two terciles were both 0 . 


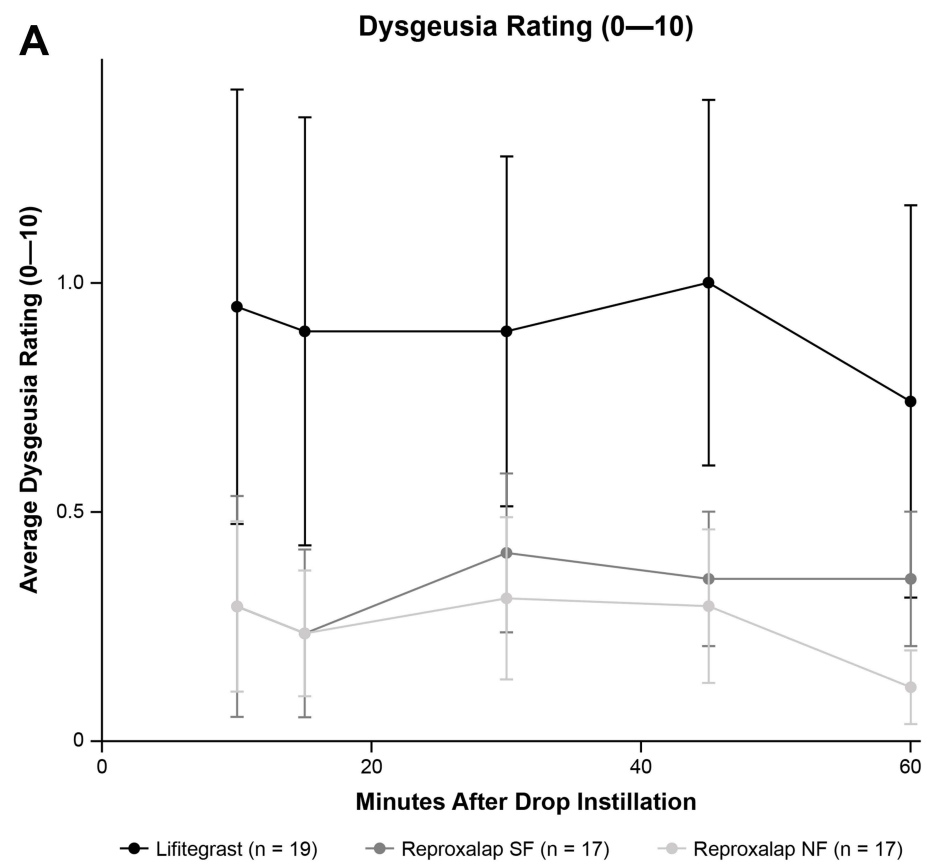

\begin{tabular}{|c|c|}
\hline \multicolumn{2}{|c|}{ Dysgeusia $P$ Values Over All Time Points } \\
\hline Reproxalap SF vs. Lifitegrast & Reproxalap NF vs. Lifitegrast \\
\hline$P=0.1042$ & $P=0.0184$ \\
\hline
\end{tabular}

B Duration of Dysgeusia Response

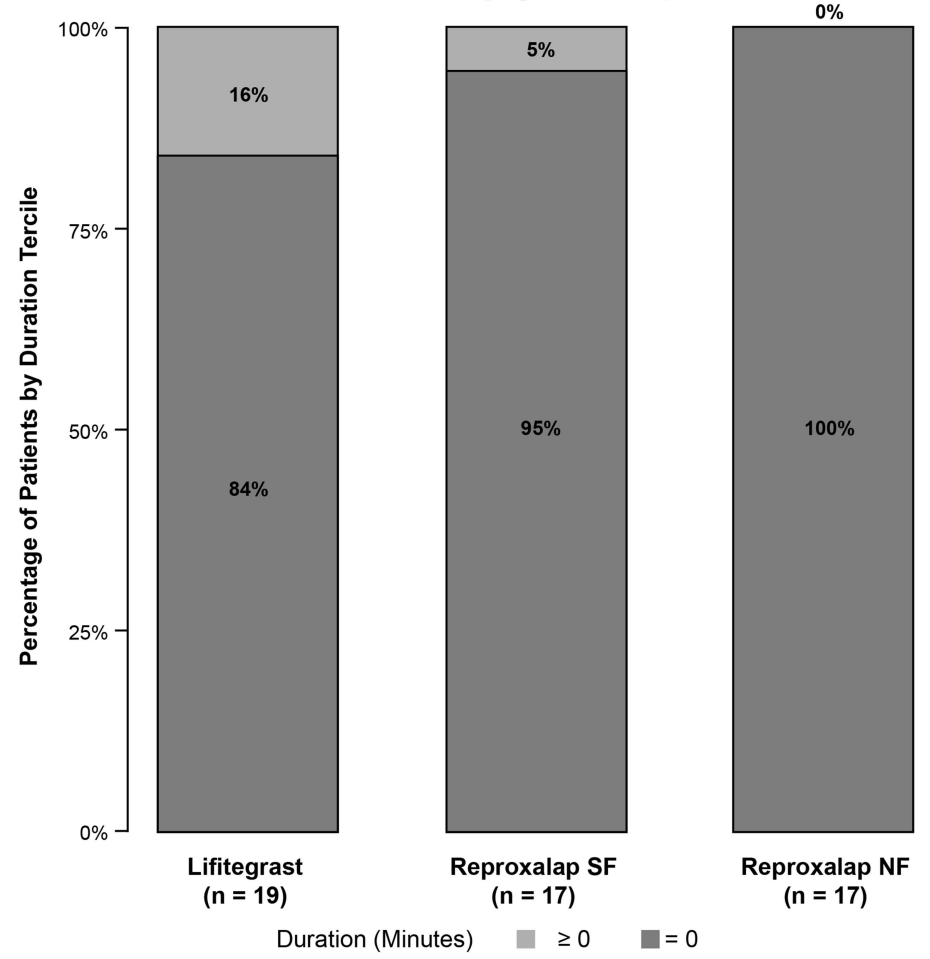

Figure 3 (A) Dysgeusia rating (0-10) of reproxalap SF and reproxalap NF versus lifitegrast. Data are plotted as means \pm SEM. (B) ODS negative responder (score of $\geq 3$ ) duration was analyzed by tercile for each treatment group. The bottom two terciles were both 0 . 
A

- Negative

- Positive

B

- Negative

Positive

C

- Negative Positive

\section{Ocular Discomfort Descriptive Assessment}

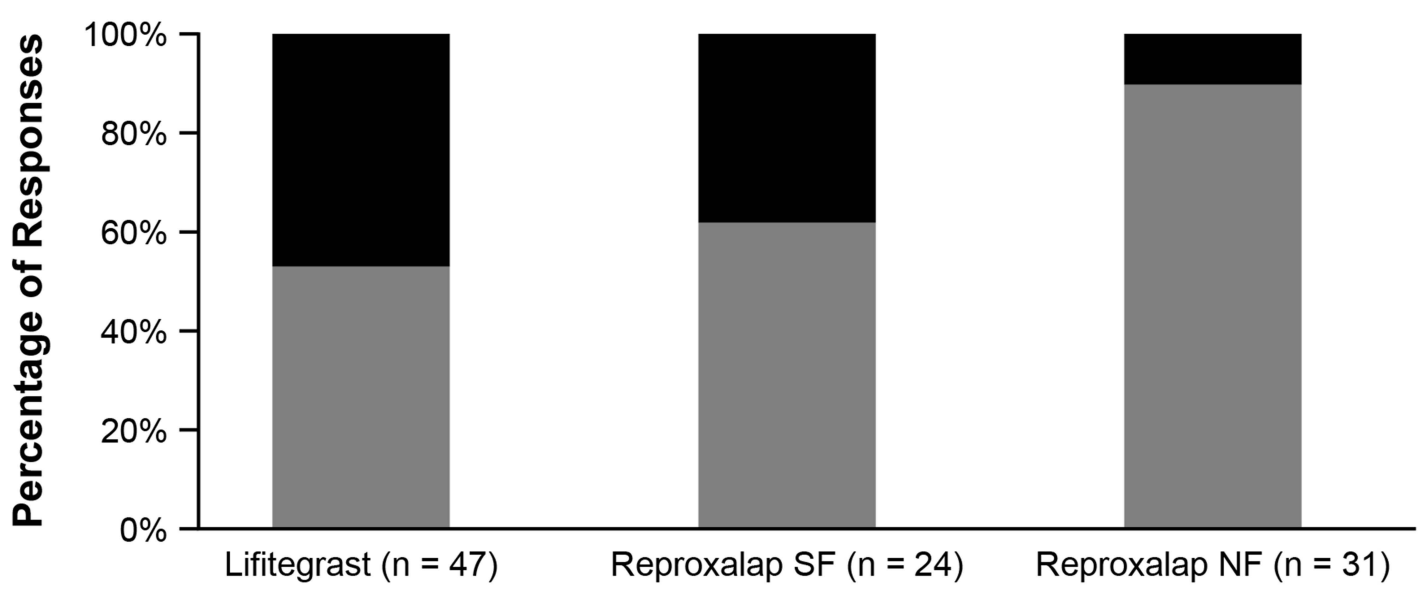

Vision Descriptive Assessment

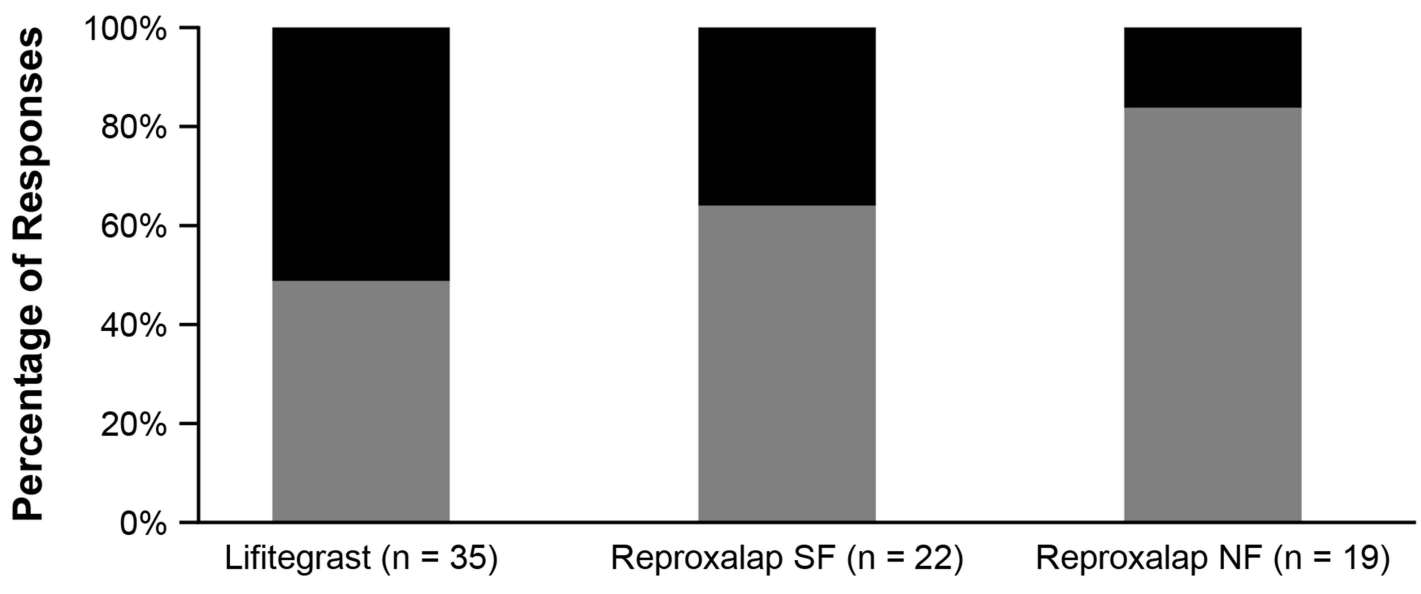

Taste Descriptive Assessment

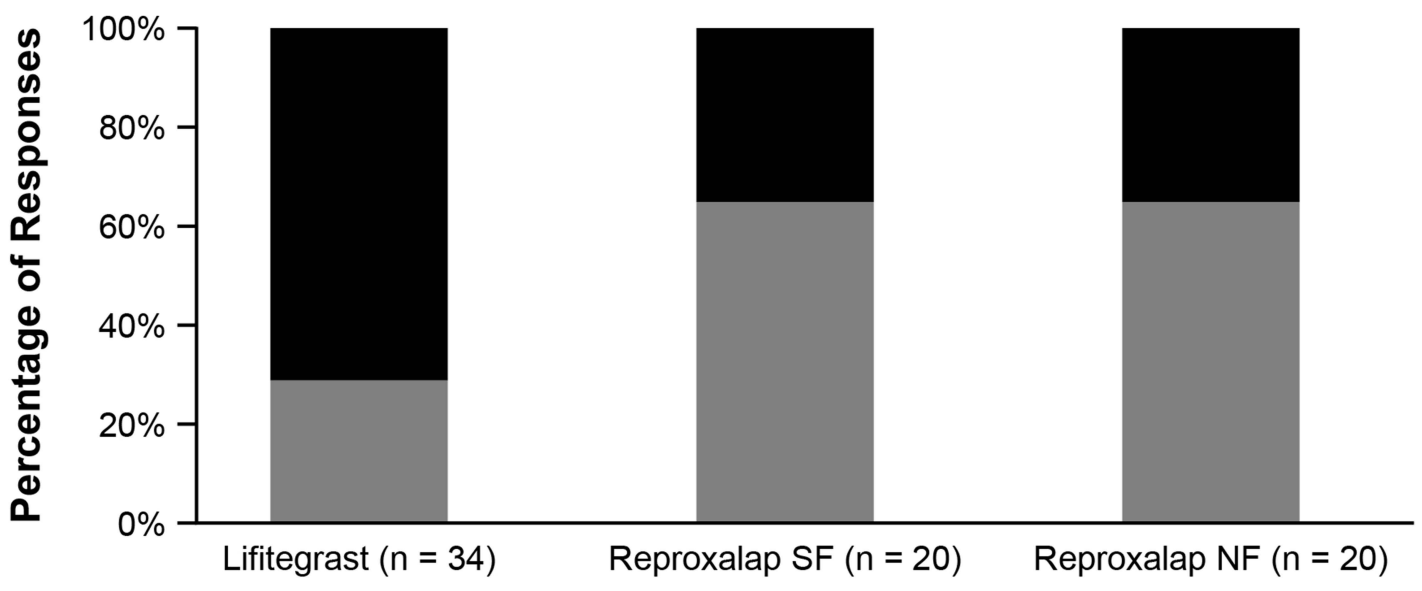

Figure 4 Eye drop comfort descriptive assessments of (A) ocular discomfort, (B) vision, and (C) taste for lifitegrast, reproxalap SF, and reproxalap NF. Descriptive term responses were categorized into positive and negative categories by descriptor category. 
A

\begin{tabular}{|c|}
\hline $\begin{array}{r}\text { Did you experience a } \\
\text { bad taste from taking } \\
\text { the study drug? }\end{array}$ \\
\hline $\begin{array}{l}\text { If yes, would the } \\
\text { bad taste reduce the } \\
\text { likelihood of you taking } \\
\text { the study drug again? }\end{array}$ \\
\hline $\begin{array}{r}\text { If yes, would the } \\
\text { bad taste prevent } \\
\text { you from taking the } \\
\text { study drug again? }\end{array}$ \\
\hline
\end{tabular}

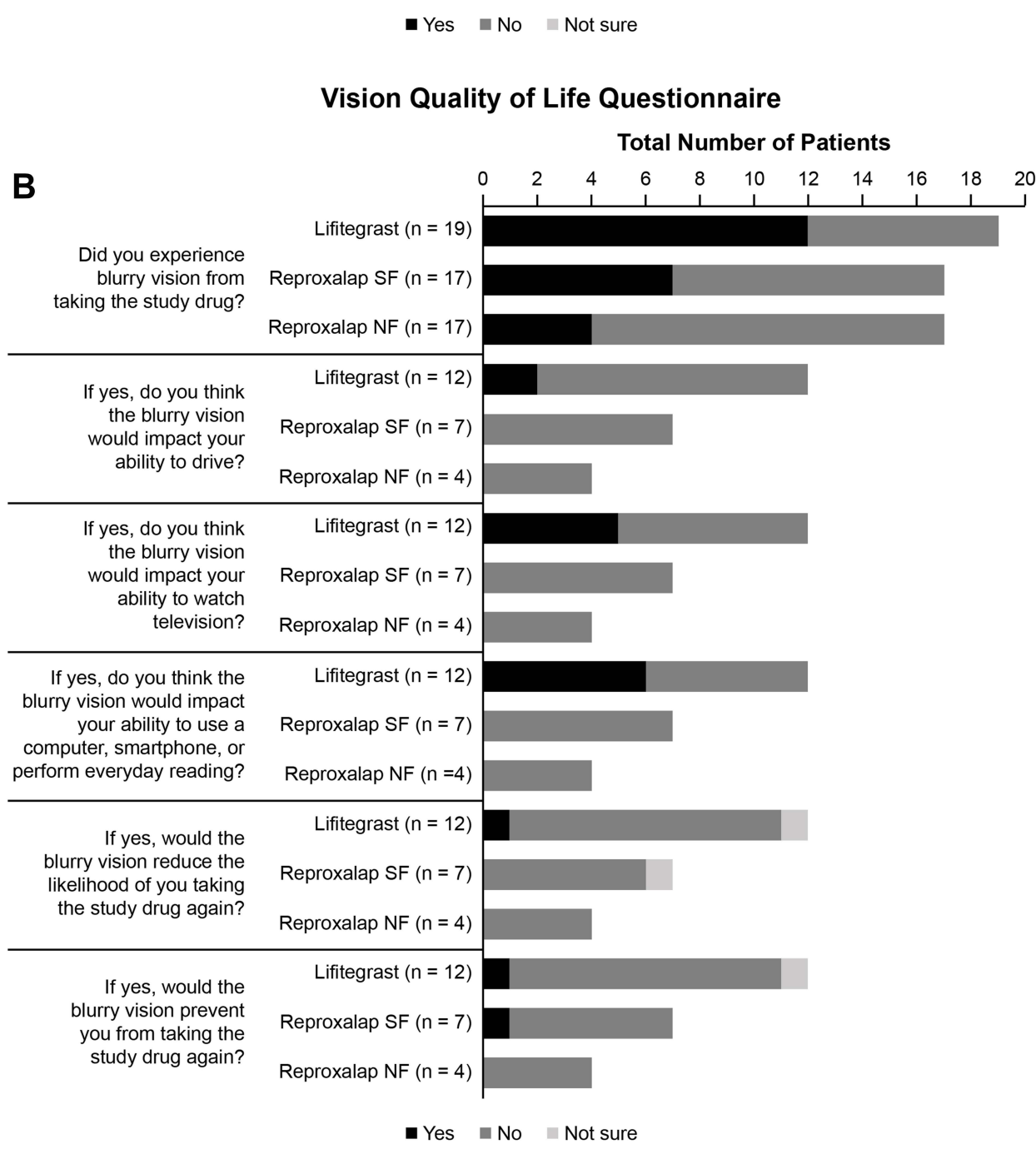

\section{Taste Quality of Life Questionnaire}

Total Number of Patients

Reproxalap SF $(n=17)$

Reproxalap NF $(n=17)$

Lifitegrast $(n=5)$

Reproxalap SF $(n=3)$

Reproxalap NF ( $n=3)$

Lifitegrast $(n=5)$

Reproxalap SF $(n=3)$

Reproxalap NF $(n=3)$
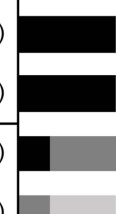

3)

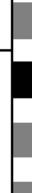

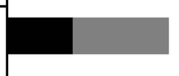

)

\section{Total Num}

$\begin{array}{lllllllll}4 & 6 & 8 & 10 & 12 & 14 & 16 & 18 & 20\end{array}$
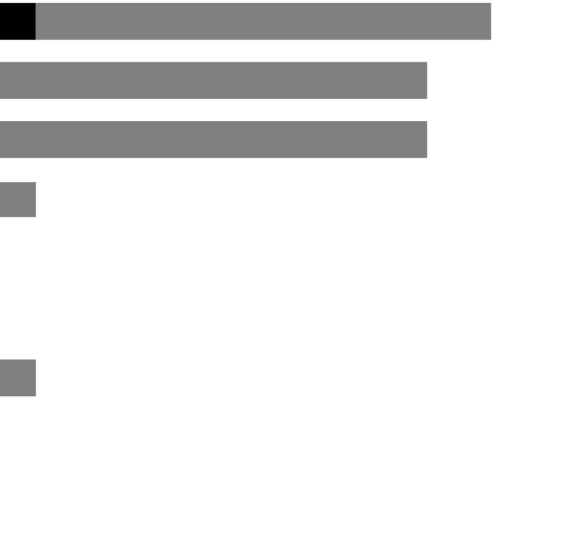
in less than 1 year. ${ }^{4}$ The results of the present clinical trial indicate that reproxalap has broad statistically significant advantages over lifitegrast in assessments of the most common lifitegrast side effects of ocular discomfort, blurry vision, and dysgeusia, and the clinical relevance of these findings was supported with responder definition analyses, which are consistent with US Food and Drug Administration guidelines for the assessment of clinical relevance. ${ }^{24}$ The superior performance of reproxalap with regard to the most commonly reported side effects of lifitegrast may result in greater patient adherence to, and lower discontinuation rates for, a novel potential prescription DED therapy.

\section{Abbreviations}

DED, dry eye disease; MMRM, mixed model repeated measures; NF, novel formulation; ODS, ocular discomfort score; QoL, quality of life; SD, standard deviation; SF, standard formulation.

\section{Data Sharing Statement}

The authors do not intend to share participant-level data. Queries or requests should be directed to the corresponding author (T. C. Brady).

\section{Ethics Approval and Informed Consent}

This trial was performed in accordance with the Declaration of Helsinki on ethical principles for medical research involving human patients, the International Council for Harmonisation Guideline on Good Clinical Practice, and all applicable local regulatory requirements and laws. Informed consent was obtained from the patients, and the research followed HIPAA regulations. This study was carried out with approval from the institutional review board Alpha IRB, San Clemente, California (approval date Nov 11, 2019). Because the trial was a Phase 1 trial conducted entirely in the United States, public registration was not required, and given the trial design, prospective registration was not deemed to be of benefit to the DED patient community.

\section{Acknowledgments}

This study was supported by Aldeyra Therapeutics, Inc, Lexington, MA, USA. Editorial/medical writing support under the guidance of the authors was provided by Christopher Goodwin, PhD, at ApotheCom, Yardley, PA,
USA, and was sponsored by Aldeyra Therapeutics, Inc, Lexington, MA, USA, in accordance with Good Publication Practice (GPP3) guidelines (Ann Intern Med. 2015;163:461-464).

\section{Author Contributions}

All authors made significant contributions to the work in the areas of study conception and design, data acquisition, or data analysis and interpretation; took part in drafting, revising, or critically reviewing the manuscript; gave final approval of the version to be published; agreed on the journal to which the article has been submitted; and agreed to be accountable for all aspects of the work.

\section{Funding}

Financial support provided by Aldeyra Therapeutics, Inc.

\section{Disclosure}

D. McMullin, D. Clark, and B. Cavanagh report employment with and stock ownership in Aldeyra Therapeutics; P. Karpecki reports consulting fees from Aerie Pharmaceuticals, Akorn, Alcon Labs, Aldeyra Therapeutics, Allergan/AbbVie, Allysta, Aurinia, Azura Ophthalmics, Bausch + Lomb, Bio-Tissue, BlephEx, Bruder Healthcare, Cambium Medical Technologies, Dompe, Eyedetec, EyeGate, Eyevance, Imprimis, Kala Pharmaceuticals, Mallinckrodt, Novartis, Oasis Medical, Oyster Point, Regener-Eyes, ScienceBased Health, Sight Sciences, SilkTech, Sun Pharmaceutical Industries, Surface Pharmaceuticals, Tarsus Pharmaceuticals, Visant Medical, and Vital Tears; T. C. Brady reports employment, patent interests (patent nos: 10588874 and 20200121591) and stock ownership with Aldeyra Therapeutics and stock ownership in F-star Therapeutics and Evoke Pharma. The authors report no other conflicts of interest in this work.

\section{References}

1. Craig JP, Nichols KK, Akpek EK, et al. TFOS DEWS II definition and classification report. Ocul Surf. 2017;15(3):276-283. doi:10.1016/j. jtos.2017.05.008

2. Farrand KF, Fridman M, Stillman I, Schaumberg DA. Prevalence of diagnosed dry eye disease in the United States among adults aged 18 years and older. Am J Ophthalmol. 2017;182:90-98. doi:10.1016/j. ajo.2017.06.033

3. Stapleton F, Alves M, Bunya VY, et al. TFOS DEWS II epidemiology report. Ocul Surf. 2017;15(3):334-365. doi:10.1016/j.jtos.2017.05.003

4. White DE, Zhao Y, Ogundele A, et al. Real-world treatment patterns of cyclosporine ophthalmic emulsion and lifitegrast ophthalmic solution among patients with dry eye. Clin Ophthalmol. 2019;13:2285-2292. doi:10.2147/OPTH.S226168 
5. McDonald M, Patel DA, Keith MS, Snedecor SJ. Economic and humanistic burden of dry eye disease in Europe, North America, and Asia: a systematic literature review. Ocul Surf. 2016;14 (2):144-167. doi:10.1016/j.jtos.2015.11.002

6. Barber L, Khodai O, Croley T, et al. Dry eye symptoms and impact on vision-related function across international task force guidelines severity levels in the United States. BMC Ophthalmol. 2018;18 (1):260. doi:10.1186/s12886-018-0919-7

7. Dana R, Bradley JL, Guerin A, Pivneva I, Evans AM, Stillman I. Comorbidities and prescribed medications in patients with or without dry eye disease: a population-based study. Am J Ophthalmol. 2019;198:181-192. doi:10.1016/j.ajo.2018.10.001

8. Han SB, Yang HK, Hyon JY, Wee WR. Association of dry eye disease with psychiatric or neurological disorders in elderly patients. Clin Interv Aging. 2017;12:785-792. doi:10.2147/CIA. $\mathrm{S} 137580$

9. Wan KH, Chen LJ, Young AL. Depression and anxiety in dry eye disease: a systematic review and meta-analysis. Eye. 2016;30 (12):1558-1567. doi:10.1038/eye.2016.186

10. Zheng Y, Wu X, Lin X, Lin H. The prevalence of depression and depressive symptoms among eye disease patients: a systematic review and meta-analysis. Sci Rep. 2017;7(1):46453. doi:10.1038/ srep46453

11. Colin J. The role of NSAIDs in the management of postoperative ophthalmic inflammation. Drugs. 2007;67(9):1291-1308. doi:10.2165/00003495-200767090-00004

12. Al Hanaineh AT, Hassanein DH, Abdelbaky SH, El Zawahry OM. Steroid-induced ocular hypertension in the pediatric age group. Eur J Ophthalmol. 2018;28(4):372-377. doi:10.1177/1120672118757434

13. Lollett IV, Galor A. Dry eye syndrome: developments and lifitegrast in perspective. Clin Ophthalmol. 2018;12:125-139. doi:10.2147/ OPTH.S126668

14. Incorporated SU.XIIDRA $A^{T M}$ (lifitegrast ophthalmic solution) $5 \%$, for topical ophthalmic use. 06/2016. MA: Shire US Incorporated; 2016.

15. Mah F, Milner M, Yiu S, Donnenfeld E, Conway TM, Hollander DA. PERSIST: physician's evaluation of restasis $\left({ }^{\circledR}\right)$ satisfaction in second trial of topical cyclosporine ophthalmic emulsion $0.05 \%$ for dry eye: a retrospective review. Clin Ophthalmol. 2012;6:1971-1976. doi:10.2147/OPTH.S30261
16. Nichols KK, Holland E, Toyos MM, et al. Ocular comfort assessment of lifitegrast ophthalmic solution $5.0 \%$ in OPUS-3, a Phase III randomized controlled trial. Clin Ophthalmol. 2018;12:263-270. doi:10.2147/OPTH.S152841

17. White DE, Zhao Y, Jayapalan H, Machiraju P, Periyasamy R, Ogundele A. Treatment satisfaction among patients using anti-inflammatory topical medications for dry eye disease. Clin Ophthalmol. 2020;14:875-883. doi:10.2147/OPTH.S233194

18. White DE, Zhao Y, Jayapalan H, Machiraju P, Periyasamy R, Ogundele A. Physician satisfaction with anti-inflammatory topical medications for the treatment of dry eye disease. Clin Ophthalmol. 2020;14:931-938. doi:10.2147/OPTH.S237832

19. Clark D, Sheppard J, Brady TC. A randomized double-masked phase 2a trial to evaluate activity and safety of topical ocular reproxalap, a novel RASP inhibitor, in dry eye disease. J Ocul Pharmacol Ther. 2021;37(4):193-199. doi:10.1089/jop.2020.0087

20. Clark D, Tauber J, Sheppard J, Brady TC. Early onset and broad activity of reproxalap in a randomized, double-masked, vehicle-controlled phase $2 \mathrm{~b}$ trial in dry eye disease. $A m$ J Ophthalmol. 2021;226:22-31. doi:10.1016/j.ajo.2021.01.011

21. Clark D, Cavanagh B, Shields AL, et al. Clinically relevant activity of the novel rasp inhibitor reproxalap in allergic conjunctivitis: the Phase 3 ALLEVIATE trial. Am J Ophthalmol. 2021;230:60-67. doi:10.1016/j.ajo.2021.04.023

22. Mandell KJ, Clark D, Chu DS, Foster CS, Sheppard J, Brady TC. Randomized Phase 2 trial of reproxalap, a novel reactive aldehyde species inhibitor, in patients with noninfectious anterior uveitis: model for corticosteroid replacement. J Ocul Pharmacol Ther. 2020;36(10):732-739. doi:10.1089/jop.2020.0056

23. Olsen MF, Bjerre E, Hansen MD, et al. Pain relief that matters to patients: systematic review of empirical studies assessing the minimum clinically important difference in acute pain. BMC Med. 2017;15(1):35. doi:10.1186/s12916-016-0775-3

24. US Food and Drug Administration. Patient-reported outcome measures: use in medical product development to support labeling claims; 2009. Available from: https://www.fda.gov/regulatory-information /search-fda-guidance-documents/patient-reported-outcome-measuresuse-medical-product-development-support-labeling-claims. Accessed August 1, 2021.
Clinical Ophthalmology

\section{Publish your work in this journal}

Clinical Ophthalmology is an international, peer-reviewed journal covering all subspecialties within ophthalmology. Key topics include: Optometry; Visual science; Pharmacology and drug therapy in eye diseases; Basic Sciences; Primary and Secondary eye care; Patient Safety and Quality of Care Improvements. This journal is indexed on PubMed

\section{Dovepress}

Central and CAS, and is the official journal of The Society of Clinical Ophthalmology (SCO). The manuscript management system is completely online and includes a very quick and fair peer-review system, which is all easy to use. Visit http://www.dovepress.com/ testimonials.php to read real quotes from published authors. 